\title{
A Fast Approach to Quantitative Evaluation of Minerals by Scanning Electron Microscopy - Application to Diverse Natural Materials and Metallurgy
}

Alexander Azenkeng, Kurt Eylands, and Patricia Kleven

Energy \& Environmental Research Center (EERC), University of North Dakota, 15 North 23rd Street, Stop 9018, Grand Forks, ND 58202-9018

A recently developed surface analytical technique, automated quantitative evaluation of minerals by scanning electron microscopy (SEM; QEMSCAN ${ }^{\circledR}$ ) [1, 2], offers a fast means of characterizing a variety of materials. The basic operation of the QEMSCAN (Figure 1) involves collecting SEM spectra on the sample and matching them with a predefined mineral list called the species identification program. Based on the matched spectra, the mineral phases and chemical composition of the material are assigned and quantified on a particle-by-particle basis at relatively short time scales, e.g., 1000 x-ray counts can be collected in $5 \mathrm{~ms}$ [1]. Fast x-ray acquisition is achieved via the incorporation of four high-speed, light element silicon drift detectors. The other main components of the system include a Carl Zeiss motherboard SEM and proprietary software for mineral classification and quantification.

The EERC has used this system to characterize a variety of natural materials, including coal, fly ash, gasification slag, deposits, and drill core samples. It is also being used to aid in $\mathrm{CO}_{2}$ sequestration studies, catalyst preparation, and metal alloy characterization. The QEMSCAN system is able to detect and quantify very small amounts $(<1 \%)$ of minerals in samples as well as generate digital images of the analyzed samples on a pixel-by-pixel, particle-by-particle basis.

In Figures 2-7, we present the results of some of the studies conducted at the EERC using the QEMSCAN. In Figures 2 and 3, digital images obtained from coal and fly ash analysis are presented and show the relative particle sizes, shapes, porosity, texture, and mineralogy. Such information is used to predict slagging and fouling behaviors of coal, and the ash analysis helps in predicting ash formation conditions in process equipment. Figure 4 shows an image of a gasification slag that indicates the mineralogy of the slag, texture, and void spaces, while in Figure 5, a thin section image of the Bakken formation showing the mineralogy and mineral zones is presented. The slag properties are used to predict their formation conditions in process equipment, and the Bakken samples show potential pore-filling minerals. New metal phases formed at the interface of a welded metal Alloy joint are shown in Figure 6; chemical compositions and the dispersion of joint-strengthening additives are also determined from the analysis. Finally, Figure 7 shows analyzed drill core samples from Williston Basin, North Dakota. A complete mineral characterization, including accessory minerals, two-dimensional grain-size data, and porosity/permeability predictions, are obtained and used to develop improved geochemical models for geological $\mathrm{CO}_{2}$ sequestration studies.

\section{References}

1. Intellection Pty Ltd. www.intellection.com (accessed November 2008).

2. FEI Company. www.fei.com (accessed February 2010).

3. The EERC Natural Materials Analytical Research Laboratory is acknowledged for financial support to attend this conference. 

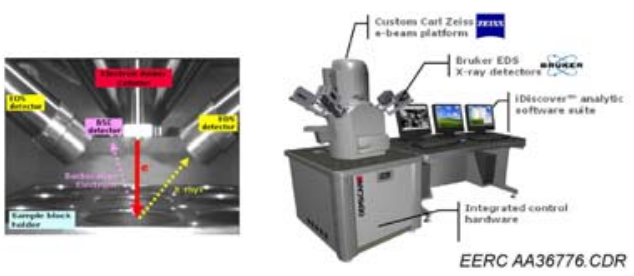

Figure 1. Main components of the QEMSCAN system.

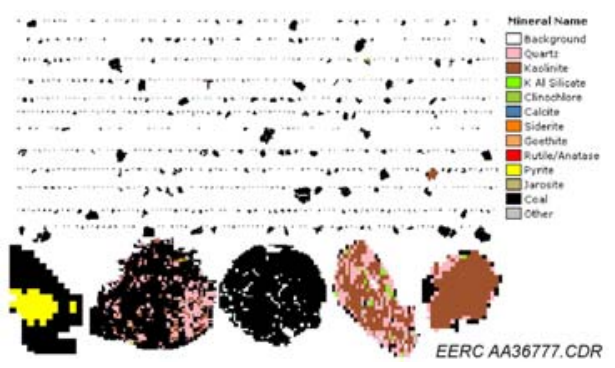

Figure 2. Analyzed coal particles show size, shape, mineralogy, texture, and porosity.

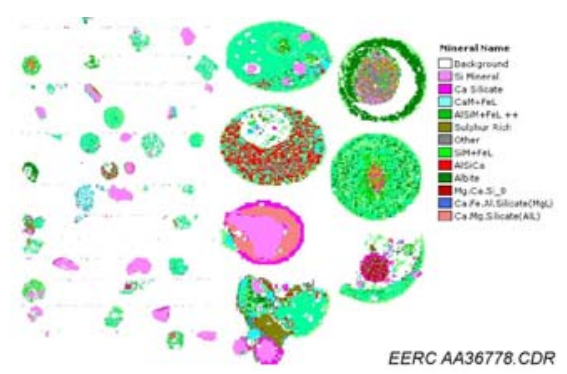

Figure 3. Analyzed fly ash particles show size, shape, mineralogy, texture, and porosity.

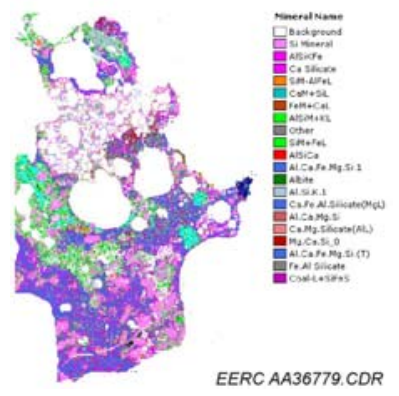

Figure 4. Image of gasification slag indicates mineralogy, texture, and porosity.

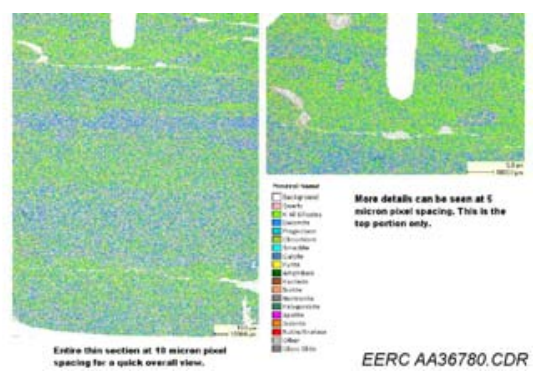

Figure 5. Bakken formation thin section shows mineral zones, types, and porosity.

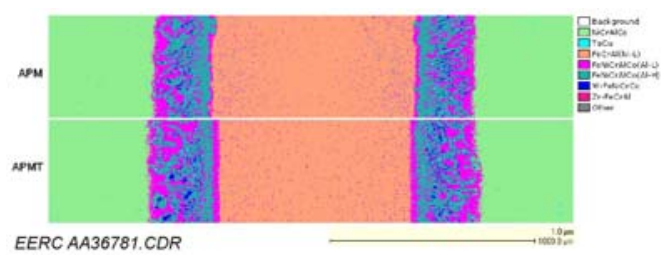

Figure 6. New metal phases formed at the interface of a welded Alloy joint.

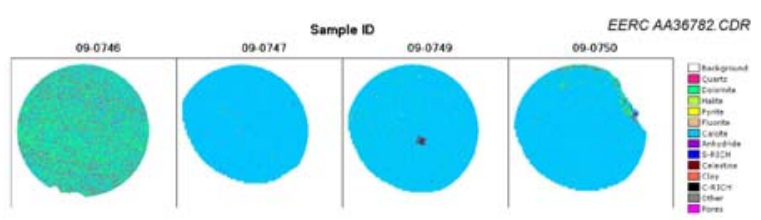

Figure 7. Drill core samples from Williston Basin, North Dakota, for geological $\mathrm{CO}_{2}$ sequestration studies. 